\title{
Correction to: Parenting as a Mediator of Associations between Depression in Mothers and Children's Functioning: A Systematic Review and Meta-Analysis
}

\author{
Sherryl H. Goodman ${ }^{1}$ [ - Hannah F. M. Simon ${ }^{1} \cdot$ Amanda L. Shamblaw ${ }^{2} \cdot$ Christine Youngwon Kim $^{1}$
}

Published online: 14 September 2020

(c) Springer Science+Business Media, LLC, part of Springer Nature 2020

\section{Correction to: Clinical Child and Family Psychology Review https://doi.org/10.1007/s10567-020-00322-4}

The original version of the article requires a correction to one of the sentences. Under the section 'Limitations', the last sentence 'Findings of no support for mediation was also deemed important as, for example, our findings suggest..' should read as below.

Also important were where we found no support for moderation of the mediation model; for example, our findings suggest that parenting as a mediator of associations between depression and child functioning is concerning regardless of the ages of the children, for both sons and daughters, and for a broad range of aspects of children's functioning.

Publisher's Note Springer Nature remains neutral with regard to jurisdictional claims in published maps and institutional affiliations.

The original article can be found online at https://doi.org/10.1007/ s10567-020-00322-4.

Sherryl H. Goodman

sherryl.goodman@emory.edu

1 Department of Psychology, Emory University, Atlanta, GA 30322, USA

2 Department of Psychology, Queen's University, Kingston, Canada 